\title{
Pensar la irrupción de la novedad sobre el abismo. Heidegger y el acontecimiento
}

Juan Pablo E. Esperón CONICET, USAL, UNLaM

Argentina

Para citar este artículo: Esperón, Juan Pablo E. «Pensar la irrupción de la novedad sobre el abismo. Heidegger y el acontecimiento».

Franciscanum 169, Vol. LX (2018): 19-37.

\section{Resumen}

Este artículo tiene por objetivo dejar asentado el carácter problemático que aparece cuando se intenta pensar la irrupción de la novedad o la singularidad. Para abordar esta cuestión, la noción de acontecimiento que Heidegger elabora nos brinda un marco teórico apropiado para comprender la aparición de la novedad cuyo carácter es la contingencia.

\section{Palabras clave}

Novedad, acontecimiento, diferencia, ontología, Heidegger.

Profesor y Doctor en Filosofía, e Investigador del CONICET en la República Argentina. Ejerce la docencia en la Universidad Nacional de La Matanza (unlam) y en la Universidad del Salvador (USAL). Es director de la Revista Académica de Filosofía Nuevo Pensamiento, dependiente del Instituto de Investigaciones Filosóficas de la Universidad del Salvador, área San Miguel. Es miembro del Centro de Estudios Filosóficos de la Academia Nacional de Ciencias de Buenos Aires. Contacto: jpesperon@hotmail.com. 


\title{
Thinking about the irruption of novelty over the abyss. Heidegger and the event
}

\begin{abstract}
The objective of this article is to set the problematic character that appears when one tries to think about the irruption of novelty or singularity. For this, the notion of event that Heidegger elaborates provides us with an appropriate theoretical framework for understanding the appearance of novelty whose character is contingency.
\end{abstract}

\section{Keywords}

Novelty, Event, Difference, Ontology, Heidegger.

\section{Introducción}

La filosofía no ha dejado de plantearse, fundamentalmente desde el siglo xx, el problema de cómo pensar la irrupción de la novedad, la posibilidad de crear o de inventar una nueva forma de pensamiento que no sea una repetición más o menos sutil o una interpretación más o menos sugerente de lo ya producido por la filosofía en su historia anterior. En este sentido es que Heidegger, entre otros filósofos de nuestro tiempo, ha hecho grandes esfuerzos para pensar la realidad fuera de los límites de las categorías tradicionales de la filosofía occidental. Debido a ello, Heidegger postula la noción de acontecimiento para abordar dos cuestiones: por un lado, el problema que el sistema hegeliano había dejado, al suponer que la filosofía ha llegado a su culminación y se ha convertido en «saber absoluto», incluyendo la totalización del saber que comprende al conjunto de la historia y su sentido. Heidegger 
rechaza decididamente esta alternativa impuesta por la coyuntura histórica y afirma la posibilidad de pensar la realidad de otro modo. Para ello postula las nociones de acontecimiento y diferencia. Por otro lado, el filósofo alemán se sirve de estas nociones también para abordar de otro modo los problemas ontológicos reunidos bajo la noción de «ser» que se han planteado en la historia de la filosofía; pues sus desarrollos cargan con un caudal tan grande de problemas, significaciones e interpretaciones, que han terminado en muchos equívocos y malos entendidos, hasta llegar al punto en que, actualmente, con la voz «ser», quizás no pueda plantearse nada nuevo. En este sentido es que, por ejemplo, Heidegger postula las nociones de acontecimiento (Ereignis) y diferencia ontológica (ontologische Differenz), y distingue esta última de la diferencia óntica para mostrar la imposibilidad de un fundamento último de la realidad tal como se ha pretendido a lo largo de la historia de la filosofía occidental. Dicha imposibilidad concierne también a los intentos del estructuralismo y el cientificismo positivista, entre otras corrientes de pensamiento, cuya pretensión de universalismos y fundamentación absoluta han fracasado en el siglo xx. Sin embargo, esto no significa la ausencia total de todos los fundamentos o que debamos renunciar a la posibilidad de pensar nuestro mundo; pues el supuesto de esta nueva perspectiva filosófica es que, si aquel se define por su inalienable y radical contingencia, entonces la realidad siempre aparecerá fundada parcialmente. De este modo, la noción de acontecimiento relacionada a la diferencia y a la contingencia posibilita fundar la realidad, pero justamente sobre la premisa de la imposibilidad de un fundamento último y absoluto.

En este sentido, es que Heidegger postula un nuevo modo de hacer filosofía cuyo carácter distintivo es el de replantear los problemas ontológicos centrales de esta actividad, a saber: «qué es la realidad» $\mathrm{y}$ «por qué hay realidad pudiendo no haberla», postulando, a su modo, un nuevo movimiento del pensamiento que tiene como eje fundamental la noción de acontecimiento y cuyo tratamiento se muestra en íntima relación con la noción de diferencia. 
Por todo ello resulta de suma relevancia para la coyuntura filosófica actual preguntarnos: ¿Qué es un acontecimiento? ¿̇sabemos qué nombramos con la noción de acontecimiento?, ¿̇la noción de acontecimiento remite al lado entitativo o al lado ontológico de la realidad de acuerdo con la ya conocida diferenciación heideggeriana?, ¿̇el acontecimiento puede ser referido o vinculado con la diferencia ontológica?, ¿̇es la diferencia el lugar originario del acontecimiento? Por otro lado, desde la perspectiva filosófica heideggeriana que este texto aborda ipara qué hablar de Ereignis?, ¿̇es una estructura trascendental que explica la constitución del sentido? o ies una estructura de donación fenoménica? o, mejor aún, ¿̇es, quizás, el Ereignis una interpretación ontológica heideggeriana para denotar esas dos cosas juntas?

Este artículo, cuyo hilo conductor girará en torno al Acontecimiento y la Diferencia, buscará echar un rayo de luz respecto a estas preguntas y así poder aprehender qué implicancias conllevan estas nociones para la compresión de la novedad en un mundo cuyo carácter contingente se nos presenta y nos afecta.

\section{El acontecimiento y la diferencia ontológica en la filosofía de Heidegger}

Para aproximarnos al sentido filosófico de la noción de acontecimiento debemos tener en cuenta que este nombra, ontológicamente, la escisión, que a su vez es relación, entre la potencia inconmensurable del despliegue del ser, y el ente, al que aquel adviene, lo configura y lo determina. El acontecimiento nombra este entre como el entrecruzamiento entre la nada, el ser y la temporalidad, es decir, el instante milagroso y misterioso en el que ocurre el estallido y despliegue de la diferencia; pues tanta es la potencia con la que el ser adviene y se alza sobre la nada que produce la diferencia y, por ende, la individuación de los entes. De ello resulta que el acontecimiento no pude ser clasificado ni se deja conceptualizar de acuerdo a los parámetros aristotélicos de género, 
especie y diferencia específica, o a los parámetros tradicionales historiográficos que suponen que todo hecho es causado por algo y produce efectos; pues el acontecimiento nombra algo previo, no en el orden temporal cronológico sino en el orden ontológico, que escapa y se rehúsa a las estructuras de clasificaciones racionales.

En este sentido, el acontecimiento irrumpe intempestivamente y pone en suspenso a la sucesión normal de los hechos. El acontecimiento nombra la original e inesperada aparición de la novedad, que en su condición esencial desestabiliza y resignifica tanto el presente como el pasado y abre inconmensurables posibilidades proyectadas hacia el futuro; por consiguiente, el acontecimiento mienta la instauración de un nuevo horizonte de sentido, es decir, conlleva una dimensión originaria en la comprensión ontológica del ser, el tiempo, las cosas y el lugar del ser-humano en este nuevo contexto. Dicho de otro modo, el acontecimiento nombra el instante, único e irrepetible, de la aparición de la novedad. En este sentido, el acontecimiento es el instante de la diferencia, o mejor aún del estallido de la diferencia. A partir de ello, Žižek define al acontecimiento como: «algo traumático, perturbador, que parece suceder de repente y que interrumpe el curso normal de las cosas; algo que surge aparentemente de la nada, sin causas discernibles, una apariencia que no tiene como base nada sólido» ${ }^{1}$. En todo acontecimiento hay, según esta definición aproximada, algo «milagroso», como una ruptura del curso natural o normal de las cosas, algo inexplicable desde el saber anterior, un «efecto que parece exceder sus causas», «un suceso que no está justificado por motivos suficientes» ${ }^{2}$. Desde esta perspectiva, «la aparición inesperada de algo nuevo, que debilita cualquier diseño estable» ${ }^{3}$ es la característica fundamental del acontecimiento.

Ahora bien, Heidegger ha hecho grandes esfuerzos para pensar más allá de los límites de las categorías tradicionales de la filosofía

\footnotetext{
S. Žižek, Acontecimiento (Madrid: Sexto Piso, 2014), 16

Cf. S. Žižek, Acontecimiento, 17.

S. Žižek, Acontecimiento, 18.
} 
occidental. De este modo, este pensador postula las nociones de acontecimiento (Ereignis) y diferencia ontológica (ontologische Differenz) y la distingue de la diferencia óntica para mostrar la imposibilidad de un fundamento último y absoluto.

¿Por qué la problematización de las nociones de acontecimiento y diferencia ontológica en el pensamiento de Heidegger resultan ser uno de los aportes más importantes para la filosofía del siglo xx y abre innumerables proyecciones al pensamiento filosófico en el siglo xxI?

Heidegger hace un análisis crítico de la historia occidental, comenzando por los antiguos griegos y llegando hasta nuestros días con el objetivo de mostrar cómo, en cada una de las etapas de la historia, la realidad se ha explicado a partir de una misma lógica. A este tipo de fundamentación la llama onto-teo-lógica y la identifica con la metafísica ${ }^{4}$. Pues, la metafísica es aquella disciplina que teoriza sobre el ente en cuanto ente, en busca de su estructura general -ontología-, y teoría del ente supremo de la cual dependen todos los demás entes -teología-. Ahora bien, Heidegger llama «historia de la metafísica» a la forma de pensar que desde Platón a Nietzsche se despliega como teoría general del ser del ente y como teoría del ente supremo (onto-teo-logía), dado que se ha olvidado al ser mismo, a favor del ser como fundamento del ente. Por lo tanto, no debemos pensar que para Heidegger hay diferentes épocas ${ }^{5}$

Recuérdese que para Heidegger la metafísica y su historia se constituye en íntima unión onto-teológica. Pues en Heidegger no hay diferentes épocas en la historia, sino que hay solo una época y es la época en la que el ser de lo ente se ha interpretado metafísicamente, es decir, la historia (Geschichte) está signada por la comprensión metafísica del ser, que en cada etapa adopta caracteres peculiares (sustancia, dios, idea, sujeto).

5 El término «época» nombra el destino histórico guiado por el ser mismo. El ser se manifiesta en el ente, pero se retiene a sí mismo en cuanto ser, puesto que solo aparece como ente, como algo que es, y en lo que es, se muestra la verdad del ente. En el ente solo hay una aparición: la de su verdad, la cual deja en sombras la revelación del ser. Este acontecimiento, en el que se detiene la aparición del ser presente en pos de la presencia de lo ente, Heidegger lo llama «época»: el exhibido ocultarse del ser. El ser se sustrae al desentrañarse en el ente y, de este modo, se retiene a sí mismo. El originario signo de esta retención está en la a-létheia. Al producirse el des-ocultamiento de todo ente, se funda el ocultamiento del ser. Pero cada época de la historia de la metafísica está pensada a partir de la experiencia del olvido del ser. El olvido del ser, que se produce en la metafísica, deriva del ser mismo. Por eso, la metafísica está destinada a constituir, a través de los entes, las distintas etapas de la historia del ser, pero dentro de un mismo y único horizonte de comprensión, el de la época metafísica. Es evidente, entonces, el nexo interior que une la metafísica con la historia, ya 
históricas, sino que hay una sola época en la historia occidental que se ha desplegado, la que nombra el término metafísica, en cuanto el prefijo metá coloca al fundamento en un «más allá» del ámbito físico; en un ámbito trascendente que impide cuestionarlo. El modo de pensar metafísico que comienza con la pregunta «qué es el ser», identifica, luego, al ser con aquel ente fundamental que justifica y causa toda existencia ${ }^{6}$. Dicha identificación es la que hace posible, a la vez, pensar al ser como fundamento. Pero al identificar al ser como fundamento de lo ente se olvida la diferencia en cuanto tal, esto es, la diferencia entre ser y ente ${ }^{7}$. Aceptado esto, se abre el camino para que un ente fundamental (i. e. la idea, dios, el sujeto) y a través de la concatenación entre causas y efectos, se constituya en fundamento y, a la vez, causa primera de la realidad efectiva. Ello constituye el olvido de la diferencia y la imposibilidad de pensar la irrupción de la novedad en cuanto tal; pues lo nuevo siempre es explicado, atribuido o fundamentado por un ente supremo, que funciona como centro organizador trascendente al tipo de realidad que se quiere explicar. Además, este ente fundamental aparece como garante de la existencia de todo ente y dador de sentido de acuerdo a la lógica de pensamiento onto-teo-lógica explicitada aquí ${ }^{8}$. Esto constituye,

que esta supone el ocultamiento necesario del ser, y aquella se define por su olvido. Pero la historia (Geschichte) es el proceso en el cual el ser ad-viene en el ente des-ocultándolo, pero ocultándose él mismo. Entonces, para Heidegger, la historia está configurada por lo que llama destino del ser, ello refiere al significado que asume en el lenguaje la noción de «ser» en una época determinada, o en una civilización; sentido del que depende la aprehensión de la realidad en general que un grupo cultural determinado tiene para relacionarse entre sí y con el mundo que lo circunda. La historia de la metafísica occidental constituye, pues, una forma propia de lenguaje para expresar esa relación asentada, de modo general, en la estructura proposicional «S es $\mathrm{P}$ ». De acuerdo a cómo se precomprenda al «es», ello determinará la relación y el modo de aprehender lo real manifestado a través del lenguaje. Es decir, que lo que está siempre en juego, en toda época, es el «entre» (zwischen) de la proposición, el «es». Ello es lo que problematiza la pregunta: ¿qué y por qué la diferencia? Tal identificación es posible porque está supuesta y opera la lógica de la identidad y de oposición metafísica.

7 Cf. J.P. Esperón, «Identidad y Diferencia. Los supuestos de la filosofía moderna», en Un nuevo pensamiento para otro mundo posible, comp. Juan Carlos Scannone, (Córdoba: Universidad Católica de Córdoba, 2010), 98 y ss.

8 Para un análisis amplio respecto de la lógica onto-teo-lógica y su relación con el principio de identidad puede consultarse: J.P. Esperón, Nietzsche, ¿̇Filósofo Metafísico? Diálogo entre Nietzsche y Heidegger en torno a pensar lo dionisíaco y el Ereignis como Zwischen: movimiento, apertura y diferencia. Acabamiento de la metafísica y tránsito hacia otro modo del pensar (Buenos Aires: UNLaM-Prometeo, 2015), segunda sección. 
para Heidegger, un acontecimiento originario que se despliega en occidente y constituye su historia; pues, para Heidegger, el modo peculiar de interrogación por el ser que acaece en la antigua Grecia resulta ser un acontecimiento novedoso para occidente; pues marca el devenir de su historia de un modo decisivo.

Luego de este diagnóstico de nuestro tiempo, Heidegger se propone sentar las bases y elaborar otro modo de pensar la realidad, diferente al onto-teo-lógico (o «fundacionalismo») que impera a lo largo de la historia de occidente; es decir, sienta las bases de lo que llamamos «posfundacionalismo». El fundacionalismo puede definirse como todas aquellas teorías que adoptan fundamentos absolutos $y_{\text {, }}$ por lo tanto, incuestionables para llevar adelante las justificaciones de su campo de estudio. Pero, además, estos fundamentos resultan ser trascendentes al sistema que se pretende justificar, es decir, se explica el campo a partir de un elemento exterior al sistema quedando este elemento fuera de cualquier intento de cuestionamiento. El antifundacionalismo, niega absolutamente la posibilidad de cualquier tipo de fundamentación. Sin embargo, el posfundacionalismo se diferencia de ambos ya que no supone la ausencia de cualquier tipo fundamento, pero sí afirma la imposibilidad de una justificación última y absoluta. El posfundacionalismo admite la posibilidad de fundamentación, pero esta es siempre provisoria y contingente. El prefijo «post» no debe comprenderse en términos temporales o como una consecuencia cronológica de los relatos historiográficos; sino que señala, por un lado, la distancia y distinción con el fundacionalismo y el antifundacionalismo; y, en segundo lugar, señala la problemática diferencial que encierra aquella noción al mostrar la contingencia radical que asume un fundar inacabado e indefinible ${ }^{9}$. Por ello, no debemos confundir al posfundacionalismo con un mero relativismo posmoderno donde cualquier fundamentación daría lo mismo, o con un nihilismo que simplemente sostenga la imposibilidad 
del fundamento como ha mostrado Nietzsche ${ }^{10}$; pues la cuestión fundamental que encierra el posfundacionalismo es convertir en problema al estatus ontológico por el cual el fundamento es considerado contingente, inacabado e indefinible.

Ahora bien, en el pensamiento heideggeriano, la ausencia de fundamento debe comprenderse como un fundar abismal, no como cancelación e imposibilidad del fundamento, sino como un fundar sobre el abismo, como un tipo de fundamentación sin fondo, sin referencias, sin cimientos; porque para Heidegger «el fundamento funda en tanto que abismo» (Der Grund gründet als Ab-grund). ${ }^{11}$ Para Heidegger el a-bismo, de algún modo, es parte constitutiva del fundar, es decir, el a-bismo está presente en el fundamento como su esenciación (Wesung). Pues en la palabra Ab-grund se juega la relación diferencial entre Grund (fundamento) y Ab-Grung (abismo). El pensador alemán pone en relación estas dos dimensiones del fundar que se relacionan y se diferencian a la vez, pues ambos elementos son constitutivos del carácter contingente de la realidad. Este nuevo modo de fundación, en términos heideggerianos, impide, justamente, identificar al fundamento con un ente determinado al modo ontoteo-lógico, que impera en la tradición de pensamiento occidental.

Entonces, desde la perspectiva que introduce Heidegger, el fundamento «funda» en cuanto se retrae o se retira; el «abismo» es este retraerse o esta demora por la cual aquel no puede resultar último ni acabado. De este modo, nunca llegará el momento de fundamentación definitiva o absoluta de la realidad, pues lo que se revela en el fundar es siempre la retirada del fundamento sobre el abismo pero que

10 Para un análisis amplio respecto de la noción de nihilismo en la filosofía de Nietzsche y la recepción heideggeriana véase: J.P. Esperón, «Fenómeno religioso y nihilismo: delimitación onto-teo-lógica de la metafísica y apertura de nuevos horizontes para una originaria vinculación con lo divino en las filosofías de Heidegger y Nietzsche», en Trascendencia y Sobreabundancia. Fenomenología de la Religión y Filosofía Primera, eds. J.C. Scannone, R. Walton, J.P. Esperón (Buenos Aires: Biblos, 2015), 49-71.

11 Las obras de Heidegger se citan según las Gesamtausgabe, 'Wege-nichtWerke', editada por Vittorio Klostermann Frankfurt an Main., Veröffentlichte Schriften (1914-1976), Vorlesungen (1923-1944), Unveröffentlichte Abhandlungen (1919-1967), aún en edición. En adelante utilizaremos la sigla GA, el número del tomo y la paginación. Para esta cita: GA 65: 29. Traducción española Aportes a la Filosofía. Acerca del Evento (Buenos Aires: Biblos, 2003), 41. 
produce, a la vez, la diferencia ontológica, o en jerga heideggeriana, la «apertura de un claro» (Lichtung) que es el lugar del acontecimiento (Ereignis). Esta noción resulta sumamente relevante en el pensamiento heideggeriano para comprender la diferencia ontológica; ya que aquella noción debe ser comprendida como Er-eignung, es decir, en un sentido procesual. Así el juego fundar-desfundar se despliega y se esencia en el Ereignis. La retirada del fundamento no implica, entonces, la ausencia total del fundamento, sino que la dimensión o el juego fundar-desfundar mienta la posibilidad de la apertura del acontecimiento, que funda, a su vez, la posibilidad contingente de la aparición de la dimensión entitativa de la realidad. El Ereignis nombra la dimensión de absoluta contingencia del juego fundar-desfundar en la que el ser se esencia y por la que su verdad se revela y acontece (se desoculta) a la vez que se retrae produciendo el estallido de la diferencia. Pero no debemos confundir el acontecimiento con el lado entitativo de la relación. El acontecimiento señala el instante mismo del movimiento fundar-desfundar que abre la posibilidad de la dimensión entitativa de la realidad pero que no se confunde con ella. El acontecimiento es la dimensión de la posibilidad contingente de la aparición de la diferencia entitativa como tal. Entonces, considerada la diferencia de este modo, el acontecimiento acontece entre la sobrevenida del ser y su retirada; y se localiza en el entre (Das Zwischen) como estallido diferencial que funda-desfundando la dimensión entitativa. El Zwischen no es un punto dentro en el tiempo o en el espacio, es el momento en que el juego fundar-desfundar acontece como estallido, dislocando y posibilitando la dimensión del espacio y el tiempo. Heidegger nombra con la forma arcaica del antiguo alemán Seyn al acontecimiento del diferenciar mismo, es decir, al acontecer de la diferencia como diferencia para distinguirla de la diferencia entre el ser y lo ente.

Ahora bien, debido a la brecha que aparece entre el nivel entitativo y el nivel ontológico, y también debido a que el nivel ontológico en cuanto fundamento ausente se sustrae, nuestra comprensión de la realidad siempre tiene un arraigo en los entes, en ellos hay rastros de la dimensión 
ontológica que podemos reconocer, recoger, señalar y seguir ya que la dimensión ontológica está presente en lo ente al modo de ausencia o abismo. En definitiva, la tarea heideggeriana no consiste en eliminar el fundamento sino en hacer problemática la dimensión misma del fundamento como un movimiento que funda sobre el abismo ${ }^{12}$.

\section{Conclusión}

De este modo Heidegger, con la noción de Ereignis, intenta pensar al ser en cuanto tal y la diferencia con lo ente, de otro modo frente a los límites categoriales de la lógica de la identidad, de la representación y de la fundamentación. La pregunta por el sentido del ser que es el hilo conductor de Ser y Tiempo se transforma, luego, en la pregunta por la verdad del ser, es decir, por el Ereignis, a partir de los Aportes a la filosofía $a^{13}$. Este tópico tiene como eje central la noción alemana Wesung que proviene de sustantivo Wesen (esencia) y que podemos traducir como «esenciarse», ya que lo que el pensador alemán quiere acentuar es el sentido procesual del sustantivo, y de este modo, verbalizarlo, imprimirle movimiento. El ser se esencia a sí mismo produciendo el acontecimiento ${ }^{14}$. Pues «el acontecimiento constituye el esenciarse (Wesung) del ser (Seyn) ${ }^{15}$. Para Heidegger el acontecimiento «es la simultaneidad espacio-temporal para el ser (Seyn) y el ente» ${ }^{16}$. Y el decir acerca de la verdad del ser es «el entre (Das Zwischen) con respecto al esenciarse del ser (Seyn) y la entidad del ente. Este "entre" funda la entidad del ente en el ser (Seyn) ${ }^{17}$. Aquí aparece el punto de dislocación en el que se produce el estallido

Para un análisis más amplio respecto de la cuestión del fundamento en la filosofía de Heidegger puede consultarse: J.P. Esperón, «El problema del fundamento, la verdad y sus límites en la tradición filosófica occidental a partir de la lectura heideggeriana», en El fundamento y sus límites. Algunos problemas de fundamentación en ciencia y filosofía, comps. Jorge Alfredo Roetti y Rodrigo Moro (Londres: College Publications of London, 2016), 205-236.

13 Beiträge zur Philosophie (von Ereignis), en Gesamtausgabe, vol. 65, Frankfurt an Main, Vittorio Klostermann, 1989. Traducción española: Aportes a la Filosofía. Acerca del Evento.

14 Cf. GA 65: 7, 13. Traducción española, 29.

15 GA 65, 8. Traducción española, 25.

16 GA 65, 13. Traducción española, 29.

17 GA 65, 13. Traducción española, 29. 
de la diferencia y, a la vez, emerge el acontecimiento como instancia singular y novedosa que no puede ser fundamentado ni explicado definitivamente.

El acontecimiento (Ereignis), entonces, es el movimiento de la diferencia que se dona en los entes y en los hombres pero que se retrae a sí mismo. La diferencia mienta "un "entre"; y este entre permanece evidentemente en toda metafísica no atendido, no considerado y no experimentado. Pero este "entre"' es lo abierto» ${ }^{18}$; por eso afirma Heidegger que lo que «intentamos pensar es el Es de este Es gibt Sein, Es gibt Zeit, el Es que da ser y tiempo» ${ }^{19}$, por ello el «Ereignis ereignet» ${ }^{20}$, es decir, el acontecimiento se expropia a la vez que se retiene o apropia a sí mismo.

En suma, el acontecimiento en Heidegger no es fundamento, tampoco puede ser pensado como consecuencia o causa de algo. Esto significa que el Ereignis no puede ser reducido o alguna causa o fundamento que lo explique. «No hay otra cosa a la que pueda ser aún referido el Ereignis, a partir de lo cual pueda ser explicado. El acontecer apropiante no es ningún resultado (Resultat) a partir de otra $\operatorname{cosa} »^{21}$. El acontecimiento es una singularidad que ad-viene, que resulta imprevisto ya que excede los límites de toda lógica de pensamiento ontoteo-lógica, cuyo carácter es fundamentar. El acontecimiento, por ende, destruye todo horizonte teleológico; por lo cual, impide cualquier intento de totalización del sentido. El acontecimiento acaece, en términos heideggerianos, sin que puedan preverse causas; él es sorpresa absoluta que no puede ser anticipada. El acontecimiento es el advenimiento y la irrupción de lo extraordinario cuyo carácter es la absoluta gratuidad. No hay un porqué, simplemente hay acontecimiento, «se da» (es gibt), como donación de ser y tiempo, que a su vez es una constelación de sentido para el hombre. De ello se sigue la gran relevancia que el 
lenguaje $\mathrm{e}^{22}$ y la hermenéutica asumen en la posición heideggeriana para la comprensión e interpretación del sentido; también para habitar el mundo e impedir, a la vez, la totalización del sentido; ya que Da-sein es fundamentalmente $D a$, el cruce o «entre» en donde el ser y los entes; los mortales, los inmortales, el cielo y la tierra se cruzan y confluyen. En este sentido, el $D a$ es el ámbito de encuentro y choque entre ser y entes, es el claro (die Lichtung) que ilumina las cosas pero ocultándose. Die Lichtung no es un escenario donde se suceden y muestran los entes sino el acontecimiento (Ereignis) del desencubrimiento de los entes y el encubrimiento del ser. Y en él está presente la diferencia ontológica como la distancia irreductible entre ser y ente como aquello que no puede ser conceptualizado ni definido. Por ello, el acontecimiento de la metafísica, como así también el de la verdad del ser, no es producto de una diferencia del entendimiento, en el primer caso; ni tampoco aquello que pueda resolverse en el ámbito gnoseológico o lingüístico, en el segundo caso. La diferencia es el acontecimiento en cuanto tal y esta diferencia, así entendida, define también la constitución ontológica y no lingüística ni gnoseológica de la verdad como A-létheia; como el movimiento del ser que des-oculta lo ente a la vez que se oculta. La verdad es el claro (Lichtung) donde al des-ocultar lo ente que ella abre ella misma se oculta.

Por ello, para Heidegger, la noción de Ereignis es una estructura trascendental que explica la constitución del sentido, por un lado; y, por otro lado, es una estructura de donación fenoménica, a tal punto que es el elemento central a partir del cual puede explicarse la correlación entre ser y entes, por un lado; ser y hombres, por el otro.

En primer lugar, el Ereignis nombra el acontecer de la diferencia entre ser y entes, y nombra al «entre» (Das Zwischen) como el punto

22 La noción de lenguaje en Heidegger debe ser entendida no en términos de la lingüística contemporánea, es decir, como relación entre el significante y el significado, o como relaciones estructurales entre signos; sino como aquel acontecimiento que nombra la verdad del ser, que en su señalar aclara y oculta. Pues desde la interpretación de Heidegger, el hombre no nombra al ser, sino que se encuentra con él y este encuentro ocurre en y a través del lenguaje como acontecimiento decisivo. El lenguaje señala el lugar del entre o el cruce del acontecimiento. 
de toque y separación entre ambos. No estamos hablando de una unión o fusión entre ambos, sino que debemos comprender al entre como aquella intimidad que correlaciona ser y entes en un mutuo pertenecerse a la vez que se despliega como separación entre ambos $(\text { Unter-Schied })^{23}$. Para Heidegger en la «intimidad del ente y el ser $»^{24}$ reina en el Ereignis donde uno no está al lado del otro sino que es un mutuo atravesarse en su diferencia. Pues, en la diferencia, ser y entes acontecen. Esto significa que el ser es del ente y el ente es del ser. Ser y entes acontecen como tales en el diferenciarse. Este mutuo diferenciarse muestra a su vez un mutuo pertenecerse. Este mutuo juego entre (Zwischen) diferenciarse y pertenecerse en un mismo (das Selbe) juego. El «entre»(Das Zwischen), donde ser y ente se diferencian y relacionan a la vez en la inter-cisión (der Unter-Schied), nombra el movimiento diferencial en el que el ser, como sobrevenida desocultante, desoculta al ente; y como llegada, entraña a su vez, el ocultamiento del ser. El «inter» (Das Zwischen) señala el punto mutuo donde la relación ser-ente se pertenecen y se separan mutuamente haciendo de una misma relación la diferencia ${ }^{25}$.

Pero también Heidegger afirma que hay una correlación entre ser y hombre. En el hombre (Dasein) hay una proyección del ser como experiencia de su condición de arrojado (Geworfenheit) pero también de pertenencia (Zugehörigkeit) al ser. El Dasein pertenece al ser a la vez que es interpelado por éste. El punto medio de toque, en el que se relacionan ser y hombre diferenciándose a la vez, es el Ereignis como acontecimiento de «apropiación», pues el ser se apropia del hombre y el hombre se apropia del ser y, de este modo, se corresponden en lo que tienen de propio el uno y el otro. El Ereignis permite que hombre y ser estén apropiados (ge-eignet). En el acontecimiento de apropiación

23 Inter-cisión. Es la es-cisión entre (del latín inter) ser y ente, que resulta inter porque a su vez están referidos el uno al otro. «La diferencia de ser y ente, en tanto que inter-cisión entre la sobrevenida y la llegada, es la resolución desencubridora y encubridora de ambas. En la resolución (Austrag) reina el claro (Lichtung) de lo que se cierra velándose y da lugar a la separación y la reunión de la sobrevenida y la llegada», GA 11, 71. Traducción española Identidad y Diferencia (Barcelona: Anthropos, 1990), 141.

24 GA 65: 46. Traducción española, 54.

25 Cfr. GA 11, 71. Traducción española, 141. 
(Er-eignis) el Dasein se apropia del ser como pro-yección y el ser se apropia del Dasein desplegándolo como el «ahí» (da) del ser (sein). Por eso Heidegger puede decir: «el hombre está apropiado-incorporado (vereignet) al ser, pero el ser está apropiado-asignado (zugeeignet) al hombre. Se trata simplemente de experienciar este hacer propio (Eignen) en que hombre y ser están apropiados uno-a-otro (einander ge-eignet), esto es, de virar hacia lo que llamamos Ereignis» ${ }^{26}$.

En suma, en la noción de Ereignis se aprecia una reelaboración del vínculo entre el Dasein y el ser; pues el planteo de las estructuras fundamentales del Dasein y el acceso al sentido a través de la comprensión del ser (Seinsverständnis) en Sein und Zeit se desliza hacia el esenciarse del ser en el que se despliega su verdad (Wahrheit des Seyns): el Ereignis. Esta reelaboración cuyo eje rector siempre es la diferencia ontológica (ontologische Differenz) y el tiempo; ya no es concebido como estructura existencial del Dasein (Zeitlichkeit), sino como donación del ser que acaece en su verdad (Temporalität), esto significa que el Dasein no juega un papel activo en la comprensión y esclarecimiento del sentido del ser como se aventura en Ser y Tiempo, sino que el Dasein conlleva, más bien, un papel pasivo, en cuanto comprende y recoge al ser y su sentido como destinación que acaece en su verdad históricamente. Así, pues, hacia el final de Sein und Zeit, Heidegger vislumbra que no es apropiado abordar la pregunta por el sentido del ser (lado ontológico de la relación) a partir de la órbita del Dasein (lado entitativo de la relación); sino que el pensador alemán se da cuenta de que debe dejar de lado la perspectiva del Dasein como punto de partida «subjetivo» para la comprensión del sentido del ser, y así poder comprender el polo de donación y retracción del ser mismo en el que se juega la síntesis de este despliegue del ser con el Dasein en un tiempo originario que excede el lado entitativo de la relación. De este modo, aparece la problematización de la diferencia ontológica (ontologische Differenz) y el Ereignis a partir de su estatus tensivo en cuanto co-pertenencia o mutua pertenencia (Zusammengehören) entre 
(Zwischen) el ser y el Dasein en el horizonte del tiempo. En este sentido, se comprende por qué Heidegger se vuelca hacia lenguaje poético para hacer filosofía, pues esta tarea implica pensar lo no pensado o, dicho de otro modo, en hacer decible lo in-decible.

\section{Reflexiones finales del autor}

Ante la radicalidad de la contingencia que caracteriza al acontecimiento, nos preguntamos icómo podríamos comprender la gratuidad que implica la contingencia del acontecimiento de otro modo que a los desarrollos escolásticos? Como es sabido, la noción de gratuidad cristiana hace referencia, desde una lógica de fundamentación onto-teo-lógica, a la presencia y existencia de un principio transcendente que crea la realidad (ex nihilo) a partir de su gracia (divina), por lo cual lo novedoso no resultaría ser tal, pues siempre es explicado y justificado de antemano. Por ende, la singularidad acontecimental resulta imposible. Pero podemos acceder el carácter gratuito del acontecimiento a través de la frase verbal estarsiendo. Pues si preguntamos ìpor qué hay acontecimiento? Podemos responder: hay acontecimiento porque está-siendo. Entonces debemos preguntarnos ¿̇qué señala la frase verbal estar-siendo respecto del acontecimiento? El «estar-siendo» resulta una frase verbal apropiada para expresar y comprender al acontecimiento en tanto expresión del entre-cruzamiento de la singularidad, el devenir y la temporalidad; pues condensa esos elementos constitutivos de aquel. El gerundio «siendo» es presente e indica duración, es decir, mantiene la tensión y co-relación entre el tiempo y el devenir, elementos propios del acontecimiento. El infinitivo «estar» marca la característica de no limitación al tiempo cronológico del acontecimiento. Además, el gerundio modifica al infinitivo; ya que el modo de «estar» del acontecimiento es «siendo». Esta frase, entonces nos pone de cara al acontecimiento ya que muestra el carácter esencial de su contingencia y de su gratuidad en cuanto no admite explicaciones y fundamentaciones últimas. El acontecimiento está-siendo y con él 
estamos aconteciendo. Ahora bien, ¿̇por qué cuando retrocedemos al punto de que solo queda la pregunta por el acontecimiento aparece el «estar-siendo»?, ¿̇cuál es su sentido?

Presentamos, a continuación, algunas caracterizaciones del «esta-siendo» que serán trabajadas y desarrolladas en próximos trabajos, porque requieren una larga meditación; y, por otro lado, nuevos problemas que han surgido de la presente reflexión en torno al tema en cuestión:

1. La pluridimencionalidad del estar-siendo tiene un estatuto transontológico.

2. La dimensión del estar-siendo acaece por fuera de todo intento de reducción técnica y racional.

3. El estar-siendo no puede ser temporalizado ni dinamizado a priori, ya que el tiempo y el devenir pueden solamente ser considerados a partir del acontecimiento.

4. El estar-siendo es previo a todo juicio pues rechaza toda norma que lo determine.

5. El estar-siendo aflora como abismo pavoroso cuya impronta emerge en la imaginación.

6. El estar-siendo repele toda otra determinación preontológica (no hay algo previo al acontecimiento).

7. El estar-siendo es inmanente, abierto, absolutamente diferente e independiente del pensar.

8. El estar-siendo es ante-predicativo.

9. El estar-siendo nombra el estatus de azaroso y radical contingencia del acontecimiento.

Por otro lado, se nos han presentado nuevos problemas; pues pareciera que se torna preciso diferenciar a: EL acontecimiento de Los acontecimientos; y si es posible diferenciarlos, mostrar qué tipo de relación hay entre ellos. El acontecimiento es el estallido, desbordamiento, expansión e interconexión de la infinita potencia de la vida que produce constelaciones de sentido parciales y provisorias. 
Por esto, puede afirmar Badiou que «el acontecimiento no es lo que sucede, sino que, en lo que sucede, devino y va a devenir» ${ }^{27}$, "pues el acontecimiento es coextensivo al devenir» ${ }^{28}$. De este modo, del acontecimiento no hay experiencia posible, pues el acontecimiento se dona como realidad pero se sustrae a toda experiencia, dado que por un lado, el fundar que produce el acontecimiento es siempre parcial e inacabado; y, por otro lado, el acontecimiento, en cuanto coextensivo al devenir cuyo punto sublime de expresión es la intensidad sobreabundante del instante, siempre se sustrae a la experiencia humana; $y$, en ese sustraerse, siempre aparecen rastros o huellas que permiten acercarnos a su comprensión. Pero la dificultad que este problema presenta es que El acontecimiento en cuanto tal permanece oculto como fenómeno por lo cual pareciera que habría que estar atentos a sus efectos para desentrañar lo que aquel conlleva; pues, ¿̇cómo sería posible el conocimiento de los acontecimientos? O mejor aún, conocer ino resultaría imposible o sería una ilusión? En suma, se presenta, también, el siguiente problema: cómo conocer lo singular en cuanto tal sin que resulte subsumido en abstracciones o generalizaciones conceptuales.

\section{Bibliografía}

Las obras de Heidegger se citan según las Gesamtausgabe, ‘WegenichtWerke', editada por Vittorio Klostermann Frankfurt an Main., Veröffentlichte Schriften (1914-1976), Vorlesungen (1923-1944), Unveröffentlichte Abhandlungen (1919-1967), aún en edición.

GA 14. Traducción española: Tiempo y Ser. Madrid: Tecnos, 2006.

GA 65. Traducción española. Aportes a la Filosofía. Acerca del Evento. Buenos Aires: Editorial Biblos, 2003.

27 A. Badiou, Lógicas de los mundos. El ser y el acontecimiento 2 (Buenos Aires: Manantial, 2008), 425.

28 A. Badiou, Lógicas de los mundos. El ser y el acontecimiento 2. 
GA 70. Traducción española: Sobre el comienzo. Buenos Aires: Editorial Biblos, 2014.

Badiou, A. Lógicas de los mundos. El sery el acontecimiento 2. Buenos Aires: Manantial, 2008.

Caputo, D. J. La debilidad de Dios: Una teología del acontecimiento. Buenos Aires: Prometeo Libros, 2014.

Esperón, J.P. «El problema del fundamento, la verdad y sus límites en la tradición filosófica occidental a partir de la lectura heideggeriana». En El fundamento y sus límites. Algunos problemas de fundamentación en ciencia y filosofía, compilado por Jorge Alfredo Roetti y Esperón, J.P. «Fenómeno religioso y nihilismo: delimitación onto-teo-lógica de la metafísica y apertura de nuevos horizontes para una originaria vinculación con lo divino en las filosofías de Heidegger y Nietzsche». En Trascendencia y Sobreabundancia. Fenomenología de la Religión y Filosofía Primera, editado por J.C. Scannone, R. Walton, R. y J.P. Esperón. Buenos Aires: Biblos, 2015.

Esperón, J.P. «Identidad y Diferencia. Los supuestos de la filosofía moderna». En Un nuevo pensamiento para otro mundo posible, compilado por J.C. Scannone. Córdoba: Universidad Católica de Córdoba, 2010.

Esperón, J.P. Nietzsche, ¿̇Filósofo Metafísico? Diálogo entre Nietzsche y Heidegger en torno a pensar lo dionisíaco y el Ereignis como Zwischen: movimiento, apertura y diferencia. Acabamiento de la metafísica y tránsito hacia otro modo del pensar. Buenos Aires: UNLaM-Prometeo, 2015.

Marchart, O. El pensamiento político posfundacional. Buenos Aires: FCE, 2009.

Moro, Rodrigo. Londres: College Publications of London, 2016.

Žižek, S. Acontecimiento. Madrid: Sexto Piso, 2014. 